Itoside A and 4-hydroxytremulacin from Dovyalis caffra and Dovyalis zeyheri

Stanstrup, Jan; Rusch, Anne-Mette; Agnolet, Sara; Rasmussen, Hasse Bonde; Mølgaard, Per; Van Staden, Johannes; Stafford, Gary I.; Stærk, Dan

Published in:

Biochemical Systematics and Ecology

DOI:

10.1016/j.bse.2010.02.006

Publication date:

2010

Document version

Early version, also known as pre-print

Citation for published version (APA):

Stanstrup, J., Rusch, A-M., Agnolet, S., Rasmussen, H. B., Mølgaard, P., Van Staden, J., Stafford, G. I., \& Stærk, D. (2010). Itoside A and 4-hydroxytremulacin from Dovyalis caffra and Dovyalis zeyheri. Biochemical Systematics and Ecology, 38(3), 346-348. https://doi.org/10.1016/j.bse.2010.02.006 


\title{
Itoside A and 4-hydroxytremulacin from Dovyalis caffra and Dovyalis zeyheri
}

\author{
Jan Stanstrup ${ }^{\mathrm{a}}$, Anne-Mette Rusch ${ }^{\mathrm{a}}$, Sara Agnolet ${ }^{\mathrm{a}}$, Hasse B. Rasmussen ${ }^{\mathrm{a}}$, Per Mølgaard ${ }^{\mathrm{a}}$, \\ Johannes van Staden ${ }^{\mathrm{b}}$, Gary I. Stafford ${ }^{\mathrm{b}}$, Dan Staerk ${ }^{\mathrm{c}, *}$ \\ a Department of Medicinal Chemistry, Faculty of Pharmaceutical Sciences, University of Copenhagen, Universitetsparken 2, DK-2100 Copenhagen, Denmark \\ ${ }^{\mathrm{b}}$ Research Centre for Plant Growth and Development, School of Biological and Conservation Science, University of KwaZulu-Natal Pietermaritzburg, Private Bag \\ X01, Scottsville 3209, South Africa \\ ${ }^{\mathrm{c}}$ Department of Basic Sciences and Environment, Faculty of Life Sciences, University of Copenhagen, Thorvaldsensvej 40, DK-1871 Frederiksberg, Denmark
}

\section{A R T I C L E I N F O}

\section{Article history:}

Received 18 September 2009

Accepted 13 February 2010

\section{Keywords:}

Dovyalis caffra

Dovyalis zeyheri

Salicaceae

Itoside A

4-hydroxytremulacin

\section{Subject and source}

Dovyalis caffra (Hook. f. \& Harv.) Sim [syn. Aberia caffra Hook. f. \& Harv.] (Salicaceae) is commonly known as kei apple (Palgrave, 1991). It is found in the eastern parts of southern Africa, and is a shrub or a small tree with edible fruits. The roots and thorns are used in African traditional medicine to treat amenorrhea and chest pain (Cumes et al., 2008), and D. caffra and other Dovyalis species are used by the Zulu to treat pain in rheumatic fever and rheumatism (Bryant, 1966). Twigs and leaves were collected in September 2008 at the University of KwaZulu-Natal Botanical Garden (S29 $\left.{ }^{\circ} 37 E 30^{\circ} 24\right)$, South Africa. A voucher specimen (accession number: Stafford $362 \mathrm{NU}$ ) has been deposited in the Herbarium at University of KwaZuluNatal, Pietermaritzburg (NU Herbarium). D. zeyheri Warb. [syn. Aberia zeyheri Sond.] (Salicaceae) is commonly known as wild apricot due to its edible fruits, and is a small to medium-sized tree found in the same regions as $D$. caffra. Leaves as well as stem bark were collected in August 2008 at the University of KwaZulu-Natal Botanical Garden (S29 $\left.{ }^{\circ} 37 \mathrm{E} 30^{\circ} 24\right)$, South Africa, and a voucher specimen (accession number: Stafford $361 \mathrm{NU}$ ) has been deposited in the above-mentioned herbarium.

\section{Previous work}

There is no literature report of phytochemical investigations of $D$. zeyheri. Fruits of $D$. caffra have been investigated for their composition of pectin and amino acids (Abdel-Fattah et al., 1975), and for the antioxidant activity of the polyphenols present

\footnotetext{
* Corresponding author. Tel.: +45 35332425; fax: +45 35332398.

E-mail address: dst@life.ku.dk (D. Staerk).
} 
in the fruit juice (Loots et al., 2006). Leaves of D. caffra have been investigated for their content of tannins (Saleh et al., 1969), and the extracts of fruits, leaves, stems, and roots have shown antibacterial activity (Basile et al., 1997; Zaki, 1975). Although alkaloids are generally uncommon in Salicaceae, two alkaloids have been identified in $D$. caffra (i.e, A. caffra) by Sayed et al. (2000), and a series of novel spermidine-alkaloids were recently isolated from Dovyalis macrocalyx, Dovyalis hebecarpa, and Dovyalis abyssinica (Staerk et al., 2003; Rasmussen et al., 2006).

\section{Present study}

Dried and ground plant material of $D$. caffra (twigs and leaves, $477 \mathrm{~g}$ ) and $D$. zeyheri (stem bark, $213 \mathrm{~g}$ and leaves, $120 \mathrm{~g}$ ) were successively extracted with a $1: 1$ mixture of dichloromethane and methanol $(4 \times 650 \mathrm{ml}$ D. caffra, $5 \times 540 \mathrm{ml}$ D. zeyheri stem bark, and $4 \times 400 \mathrm{ml}$ D. zeyheri leaves $)$ and pure methanol $(2 \times 900 \mathrm{ml}$ D. caffra and $3 \times 750 \mathrm{ml}$ D. zeyheri stem bark $)$. The combined extracts were dried in vacuo and the residues (57 g D. caffra, $16 \mathrm{~g}$ D. zeyheri stem bark, and $17 \mathrm{~g} D$. zeyheri leaves) were dissolved in a 9:1 mixture of methanol and water and defatted with light petroleum to afford $35 \mathrm{~g}$, $14 \mathrm{~g}$, and $15 \mathrm{~g}$ defatted extract, respectively. The defatted extract from $D$. caffra was dissolved in $300 \mathrm{ml}$ of water and extracted with $3 \times 100$ $\mathrm{ml}$ dichloromethane and followed by extraction with $3 \times 100 \mathrm{ml}$ ethyl acetate. During this procedure $390 \mathrm{mg}$ of precipitate was obtained, which was identified as 4-hydroxytremulacin (1) (Fig. 1) by comparison of ${ }^{1} \mathrm{H}$ and ${ }^{13} \mathrm{C}$ NMR data with data from the literature (Rasmussen et al., 2006). Half (2.25 g) of the ethyl acetate fraction ( $4.5 \mathrm{~g})$ was subjected to vacuum liquid chromatography $(16 \times 4 \mathrm{~cm}$ i.d. column, Merck silica gel $60(15-40 \mu \mathrm{m})$, eluted with step-gradients of 5,10 , and $20 \%$ methanol in dichloromethane) to afford four fractions ( $\left.\mathrm{VLC}_{1} \mathrm{~A}-\mathrm{VLC}_{1} \mathrm{D}\right)$, of which fraction $\mathrm{VLC}_{1} \mathrm{~A}$ (eluted with $500 \mathrm{ml} 5 \%$ methanol and $200 \mathrm{ml} \mathrm{10 \%} \mathrm{methanol} \mathrm{in} \mathrm{dichloromethane)} \mathrm{was} \mathrm{combined} \mathrm{with} \mathrm{the} \mathrm{other} \mathrm{half} \mathrm{of} \mathrm{the} \mathrm{ethyl} \mathrm{acetate} \mathrm{extract.} \mathrm{The} \mathrm{combined}$ extract was chromatographed using the same VLC column, but with a less steep step-gradient (5, 7.5, 10, 15, and 20\% methanol in dichloromethane) to afford six fractions ( $\mathrm{VLC}_{2} \mathrm{~A}-\mathrm{VLC}_{2} \mathrm{~F}$ ). Fraction $\mathrm{VLC}_{2} \mathrm{E}(700 \mathrm{mg}$ ) was identified as itoside $\mathrm{A}(\mathbf{2})$, by comparison of ${ }^{1} \mathrm{H}$ and ${ }^{13} \mathrm{C}$ NMR data with data from the literature (Chai et al., 2007). The isolated material corresponds to $0.6 \mathrm{mg} / \mathrm{g}$ of dry plant material $(0.06 \% \mathrm{w} / \mathrm{w})$ for 1 and $3 \mathrm{mg} / \mathrm{g}(0.3 \% \mathrm{w} / \mathrm{w})$ for 2 .

The defatted extract of $D$. zeyheri stem bark was partitioned between water, dichloromethane, and ethyl acetate as described above, and the ethyl acetate fraction $(1.68 \mathrm{~g})$ was subjected to VLC $(8 \times 3 \mathrm{~cm}$ i.d. column, Merck silica gel 60 $(15-40 \mu \mathrm{m})$ eluted with step-gradients of 5, 10, and 20\% methanol in dichloromethane) to afford six fractions $\left(\mathrm{VLC}_{3} \mathrm{~A}-\mathrm{VLC} \mathrm{C}_{3} \mathrm{~F}\right)$. Fraction $\operatorname{VLC}_{3} \mathrm{C}(580 \mathrm{mg})$ was identified as 4-hydroxytremulacin (1). A portion (6.1 $\left.\mathrm{mg}\right)$ of fraction VLC $\mathrm{V}_{3} \mathrm{D}(450 \mathrm{mg})$ was separated at $40{ }^{\circ} \mathrm{C}$ by RP-HPLC $\left(150 \times 4.6 \mathrm{~mm}\right.$ i.d. Phenomenex $\mathrm{C}_{18}$ (2) Luna column $\left.(3 \mu \mathrm{m}, 100 \AA)\right)$, using isocratic elution (water-methanol 11:9+ $0.1 \%$ formic acid) with a flow rate of $0.8 \mathrm{ml} / \mathrm{min}$. Collection of one peak $\left(\mathrm{t}_{\mathrm{R}} 3.9 \mathrm{~min}\right)$ afforded $1.2 \mathrm{mg}$ of material that was identified as itoside $\mathrm{A}(\mathbf{2})$. The isolated material corresponds to $2.7 \mathrm{mg} / \mathrm{g}$ of dry plant material $(0.06 \% \mathrm{w} / \mathrm{w})$ for 1 and $0.4 \mathrm{mg} / \mathrm{g}(0.04 \% \mathrm{w} / \mathrm{w})$ for 2 .

A portion $(1.5 \mathrm{mg})$ of the defatted extract of $D$. zeyheri leaves was separated at $40{ }^{\circ} \mathrm{C}$ by RP-HPLC $(150 \times 10 \mathrm{~mm}$ i.d. Phenomenex $\mathrm{C}_{18}(2)$ Luna column $\left.(3 \mu \mathrm{m}, 100 \AA)\right)$ using the same solvent composition as above with a flow rate of $3.78 \mathrm{ml} / \mathrm{min}$. Peak $1\left(t_{R} 3.7 \mathrm{~min}, 0.7 \mathrm{mg}\right.$ ) was identified as itoside A (2), and peak 2 ( $\mathrm{t}_{\mathrm{R}} 6.6 \mathrm{~min}, 0.4 \mathrm{mg}$ ) was identified as 4-hydroxytremulacin (1).

\section{Chemotaxonomic importance}

The genus Dovyalis has traditionally been placed in the family Flacourtiaceae, which has long been recognized as a polyphyletic taxon, having a highly diverse and controversial circumscription (Chase et al., 2002). However, the cyanogenic tribes of Flacourtiaceae were recently included in the family Achariaceae, and the noncyanogenic tribes, including Dovyalis, were united with Salicaceae (APG II, 2003). Phenolic glycosides such as tremulacin, salicortin (a debenzoyl derivative of

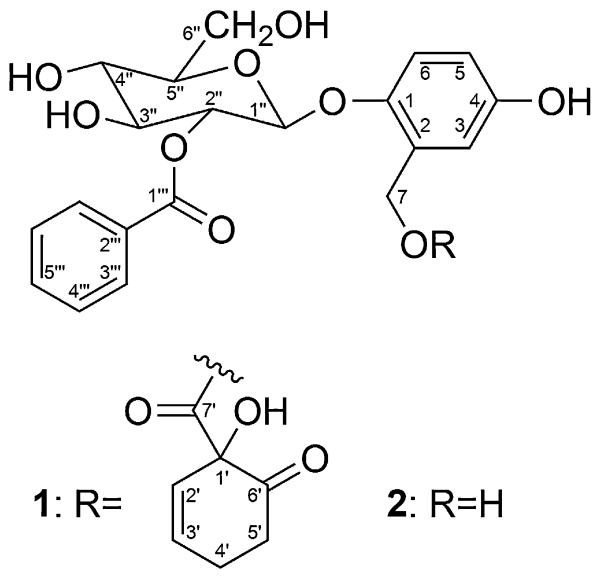

Fig. 1. Chemical structures of compounds 1-2 
tremulacin), salicin, and their derivatives are known to be characteristic markers of many Salicaceous species (Nyman and Julkunen-Tiitto, 2005), and may be of common occurrence in the extended Salicaceae (Leskinen and Alström-Rapaport, 1999). An interesting common feature of the redefined Salicaceae is that many of the species included are host plants for the same genera of specialist butterflies (Nandi et al., 1998). The clue for this preference may very likely be the common occurrence of salicin derivatives. In this work, 4-hydroxytremulacin (1) was identified as a major constituent of both $D$. caffra and $D$. zeyheri. Until now 1 has only been identified in two genera within Salicaceae, i.e., Dovyalis [D. abyssinica and D. hebecarpa (Rasmussen et al., 2006)] and Itoa [Itoa orientalis (Chai et al., 2007, 2008)]. Compounds with 4-hydroxysalicin (= salirepin) as the core skeleton are frequently found in Salicaceae, but there have also been a few reports of these compounds in Achariaceae, Symplocaceae, Liliaceae, and Hypoxidaceae (see Supplementary data). Interestingly, however, is the fact that salirepin analogues with the 1-hydroxy-6-oxocyclohex-2-enecaboxylate moiety at C-7 are restricted to Salicaceae, and they should therefore be considered important Salicaceous chemical markers (see Supplementary data). A salirepin analogue with a related 1,2,6-trihydroxy-5-oxocyclohex-3-enecarboxylate moiety has been reported from Homalium longifolium (Shaari and Waterman, 1995) and has more recently been identified in stems of Scolopia braunii by Mosaddik et al. (2007). Both species belong to Salicaceae. Itoside A (2) is a 2-benzoyl analogue of salirepin, but due to the appearance of salirepin analogues outside Salicaceae, this compound is not a unique Salicaceous chemical marker. However, as a possible precursor of $\mathbf{1}$ its presence is an important finding, and the occurrence of both phenolic glycosides $\mathbf{1}$ and $\mathbf{2}$ in $D$. caffra and D. zeyheri supports the inclusion of these species in the extended Salicaceae. The spermidine-alkaloids found in D. macrocalyx, D. hebecarpa, and D. abyssinica (Staerk et al., 2003; Rasmussen et al., 2006) were neither identified in D. caffra or D. zeyheri, and the unusual occurrence of these rare alkaloids in Salicaceae continues therefore to be an interesting chemotaxonomic aspect of Dovyalis systematics worth further investigations.

\section{Acknowledgements}

The National Research Foundation of South Africa and the University of KwaZulu-Natal are thanked for financial assistance. HPLC-equipment was purchased via a grant from The Carlsberg Foundation (Copenhagen).

\section{Appendix. Supplementary data}

Supplementary data associated with this article can be found, in the online version, at doi:10.1016/j.bse.2010.02.006.

\section{References}

Abdel-Fattah, A.F., Zaki, D.A., Edress, M., 1975. Qual. Plant. - Plant Foods Human Nutr. 24, 311.

APG II, 2003. Bot. J. Linn. Soc. 141, 399.

Basile, A., Vuotto, M.L., Violante, U., Sorbo, S., Martone, G., Castaldo-Cobianchi, R., 1997. Int. J. Antimicrob. Agents 8, 199.

Bryant, A.T., 1966. Zulu Medicine and Medicine Men. Struik, Cape Town, SA.

Chai, X.-Y., Song, Y.L., Xu, Z.R., Shi, H.M., Bai, C.C., Bi, D., Wen, J., Li, F.F., Tu, P.F., 2008. J. Nat. Prod. $71,814$.

Chai, X.-Y., Xu, Z.-R., Ren, H.-Y., Shi, H.-M., Lu, Y.-N., Li, F.-F., Tu, P.-F., 2007. Helv. Chim. Acta. 90, 2176.

Chase, M.W., Zmarzty, S., Lledo, M.D., Wurdack, K.J., Swensen, S.M., Fay, M.F., 2002. Kew. Bull. 57, 141.

Cumes, D., Loon, L., Bester, D., 2008. Healing Trees and Plants of the Lowveld. Inward Bound Press, California, USA.

Leskinen, E., Alström-Rapaport, C., 1997. Plant Syst. Evol. 215, 209.

Loots, D.T., van der Westhuizen, F.H., Jerling, J., 2006. J. Agric. Food Chem. 54, 1271.

Mosaddik, M.A., Forster, P.I., Booth, R., Waterman, P.G., 2007. Biochem. Syst. Ecol. 35, 166.

Nandi, O.I., Chase, M.W., Endress, P.K., 1998. Ann. Miss. Bot. Gard. 85, 137.

Nyman, T., Julkunen-Tiitto, R., 2005. Phytochemistry 66, 2836.

Palgrave, K.C., 1991. Trees of Southern Africa, 2. ed. Struik Publishers, Cape Town, SA.

Rasmussen, B., Nkurunziza, A.-J., Witt, M., Oketch-Rabah, H.A., Jaroszewski, J.W., Staerk, D., 2006. J. Nat. Prod. 69, 1300.

Saleh, N.A.M., El Sherbeiny, A.E.A., El Sissi, H.I., 1969. Qual. Plant. Mater. Veg. 17, 384.

Sayed, H.M., Bishay, D.W., Yousef, S.A., Kamel, M.S., Abdel-Salam, R.M., 2000. Indian J. Chem. $39 B, 215$.

Shaari, K., Waterman, P.G., 1995. Nat. Prod. Lett. 7, 243.

Staerk, D., Witt, M., Oketch-Rabah, H.A., Jaroszewski, J.W., 2003. Org. Lett. 5, 2793.

Zaki, D., 1975. Planta Med. 27, 330. 